This is the author's final, peer-reviewed manuscript as accepted for publication. The publisher-formatted version may be available through the publisher's web site or your institution's library.

\title{
Cross-country comparison of pomegranate juice acceptance in Estonia, Spain, Thailand, and United States
}

Kadri Koppel, Edgar Chambers IV, Laura Vázquez-Araújo, Loreida Timberg, Ángel Carbonell-Barrachina, Suntaree Suwonsichon

\section{How to cite this manuscript}

If you make reference to this version of the manuscript, use the following information:

Koppel, K., Chambers, E. IV, Vázquez-Araújo, L., Timberg, L., Carbonell-Barrachina, A., \& Suwonsichon, S. (2014). Cross-country comparison of pomegranate juice acceptance in Estonia, Spain, Thailand, and United States. Retrieved from http://krex.ksu.edu

\section{Published Version Information}

Citation: Koppel, K., Chambers, E. IV, Vázquez-Araújo, L., Timberg, L., CarbonellBarrachina, A., \& Suwonsichon, S. (2014). Cross-country comparison of pomegranate juice acceptance in Estonia, Spain, Thailand, and United States. Food Quality and Preference, 31, 116-123.

Copyright: (c) 2013 Elsevier Ltd.

Digital Object Identifier (DOI): doi:10.1016/j.foodqual.2013.03.009

Publisher's Link: http://www.sciencedirect.com/science/article/pii/S0950329313000451

This item was retrieved from the K-State Research Exchange (K-REx), the institutional repository of Kansas State University. K-REx is available at http://krex.ksu.edu 
Cross-Country Comparison of Pomegranate Juice Acceptance in Estonia, Spain, Thailand, and United States

\footnotetext{
Kadri Koppel ${ }^{\text {a,b,c }}$, Edgar Chambers IV a , Laura Vázquez-Araújo ${ }^{\text {d }}$, Loreida Timberg b,c, Ángel Carbonell-Barrachina ${ }^{\mathrm{d}}$, Suntaree Suwonsichon ${ }^{\mathrm{e}}$

${ }^{a}$ The Sensory Analysis Center, Department of Human Nutrition, Kansas State University, Manhattan, KS 66506-1407, USA

${ }^{b}$ Tallinn University of Technology, Department of Food Processing, Ehitajate tee 5, 19086, Tallinn, Estonia

${ }^{\mathrm{c}}$ Competence Center of Food and Fermentation Technologies, Akadeemia tee 15B, Tallinn, Estonia

${ }^{\mathrm{d}}$ Departamento de Tecnología Agroalimentaria, Grupo Calidad y Seguridad Alimentaria, Universidad Miguel Hernández, 03312-Orihuela, Alicante, Spain ${ }^{\mathrm{e}}$ Kasetsart University, Sensory and Consumer Research Center, Department of Product Development, 50 Paholyothin Road, Jatujak, Bangkok 10900, Thailand.
}

Corresponding author: Kadri Koppel, email: kadri@ksu.edu, phone: +1-785-5320163. Address: The Sensory Analysis Center, Department of Human Nutrition, Kansas State University, Manhattan, KS 66506-1407, USA. 


\begin{abstract}
The objective of this study was to compare acceptance of different flavor combinations across countries, determine consumer clusters across countries and identify drivers of liking for a healthy product (pomegranate juice). Five pomegranate juices varying in flavor character were evaluated by consumers in Estonia, Spain, Thailand, and the United States. In this study the consumers evaluated overall acceptability and flavor, sweet, sour, fruity, and pomegranate flavor liking. Also, Just About Right (JAR) questions were answered for those same attributes. The results suggested that although some samples varied in their liking across countries, larger differences in acceptance were found between consumer clusters across countries. These data suggest that individual consumer variation is greater than country specific variation. In addition, factors such as taste sensitivity or prior exposure rather than flavor are important in acceptability of pomegranate juices.
\end{abstract}

Keywords: pomegranate juice, acceptance, consumer, flavor 
1. Introduction

In recent years there has been an increase in the awareness of health benefits of products such as pomegranate fruits and supplements. Because of market demand various products made from those healthful ingredients have become available. Pomegranate juice is one of various products that provides a simple and convenient way to consume biologically active nutrients (Viuda-Martos, Férnandez-López, \& Pérez-Álvarez, 2010). However, within a healthful product category such as pomegranate juice, there is a wide selection of flavor profiles available (Koppel \& Chambers, 2010).

Some studies have concentrated on international food flavor characterization. For example, green teas, the consumption of which is considered healthy and is growing in popularity, were studied for acceptance in three countries (Lee et al., 2010). Green tea was considered a traditional product in two (Thailand and Korea) and non-traditional, but healthy in one country (USA). While different flavors were preferred in different countries, bitterness was disliked everywhere. Another example is a study conducted by Oupadissakoon, Chambers, and Chambers (2009), in which the sensory properties of ultra-high-temperature milks from different countries were compared. These authors reported that production technology of that product may have more impact on the product characteristics than local raw material quality. Neely, Lee, and Lee (2010) studied a soy-based extruded snack food with U.S. and Indian consumers and found that individual preferences were more important than cultural factors.

Consumer satisfaction has been studied with various blended juices, for example in the study by Vázquez-Araújo, Chambers, Adhikari, and CarbonellBarrachina (2010) consumer liking of pomegranate juice mixed with other juices was 
researched and the authors found that juice mixtures containing $90 \%$ pomegranate and $10 \%$ blackberry or raspberry juice were highly liked by US consumers. The liking of mixed fresh and healthy juices was studied by Endrizzi, Pirretti, Calo, and Gasperia (2009). In their study pomegranate, pineapple, apple, orange, and blood orange juices were mixed with strawberry, raspberry, blackberry, red currant, and blueberry juices; Italian consumers disliked mixtures with pomegranate juice and liked pineapple and blood orange mixes best. The results of those two studies suggest that country or cultural differences as well as reactions to some flavors can play a part in pomegranate juice acceptance.

Possible beneficial effects to health probably drive the consumption of pomegranate juices. However, repurchase is more likely if the flavor of the product was liked (Moskowitz, Gofman, \& Beckley, 2006). In addition, cultural differences may cause variations in liking patterns (Rozin, Fischler, Imada, Sarubin, \& Wrzesniewski, 1999). Our hypothesis was that segments exist that are independent of country borders and may be similar or different based on familiarity with the product category. The objective of this study was to determine how consumers from different cultures (Estonia, Spain, Thailand, and the US) accept taste and flavor combinations of a healthy juice, whether clusters of consumers exist across countries, and what drives flavor liking among consumers. 


\section{Materials and Methods}

\subsection{Samples}

Five samples, representing the five flavor clusters reported by Koppel and Chambers (2010), were acquired from Estonia, Spain, US, and Thailand (Table 1). Four samples (B, C, D, and E) had been used in the study by Koppel and Chambers (2010). One sample (B) was delayed in customs when shipping to Thailand and an available local sample with a similar flavor profile that represented the same cluster was substituted and referred to as B1. Two samples (A, B1) were used to represent clusters from the earlier study based on cluster descriptors given by Koppel and Chambers (2010), but were not part of that study. Sample E was a pomegranate juice concentrate, diluted with purified water, with a ratio of 1 (concentrated juice) : 3 (water). All samples were purchased from grocery stores or ordered in bulk, except for sample C, which was provided by Granadas de Elche (Alicante, Spain). All samples were within the use by date and were stored at room temperature, as indicated on the packaging, until testing and sent to each of the participating countries by mail.

\subsection{Descriptive Sensory Analysis}

For this study, the flavor profile of each sample (A, B, B1, C, D, and E) was tested on the same lot used for consumer testing. Each of the six profile panelists had more than $120 \mathrm{~h}$ of training in descriptive sensory testing and at least $1000 \mathrm{~h}$ experience in descriptive sensory analysis, including fruits and juices. The procedure and lexicon used in descriptive profiling was the same as that used by Koppel and Chambers (2010). Attribute intensities were evaluated on a scale, where $0=$ none and 15 = very high. Panelists evaluated the samples individually, but the final flavor profile was agreed upon as a result of a discussion led by the panel leader, following 
the consensus flavor profile approach. Similar procedures have been used by BettGarber, Lea, Champagne, and McClung (2012), Suwonsichon, Chambers, Kongpensook, and Oupadissakoon (2012), and Adhikari, Chambers, Miller, Vázquez-Araújo, Bhumiratana, and Philip (2011). All of the samples (A, B, B1, C, D, and E) were tested both at room temperature $\left(20-22^{\circ} \mathrm{C}\right)$ and chilled $\left(5-7^{\circ} \mathrm{C}\right)$. This was done to confirm a) presence of key flavor attributes that resulted in different flavor clusters as shown by Koppel and Chambers (2010), and b) presence of key flavor attributes at both temperatures as the juice may be consumed chilled by the consumers and was served as such $\left(5-7^{\circ} \mathrm{C}\right)$ during the consumer study.

\subsection{Consumer Study}

Consumer acceptance was studied in Estonia, the US, Spain, and Thailand. These countries were selected based on availability for collaborators and locations on different continents (Europe vs. North America vs. Asia) that enabled study of traditional and familiar vs. not traditional flavors and cultures where consumers are health-oriented. In addition pomegranates are locally grown in Spain and USA, in minor quantities in Thailand, but not in Estonia. The studies took place December 2010 in US and Estonia, January 2011 in Spain, and February 2011 in Thailand. Approximately 100 consumers (US $n=101$, Thailand $n=110$, Estonia $n=102$, Spain $\mathrm{n}=100$ ), with a ratio of 60 (women) : 40 (men), respectively, were recruited in each country for a central location test.

All participating consumers in all participating countries were recruited via emails and fliers. Consumers had to complete a screener stating their gender, age, and diet restrictions or allergies. Consumers were asked about juice consumption frequency and willingness to taste pomegranate juice from a selection of juices. 
Consumers who stated they were 18-64 years old, drank any kind of juice at least two times per week, had no diet restrictions or allergies, and were willing to taste pomegranate juice were recruited for testing.

The ballots, screeners, and demographic questionnaires were translated from English to Estonian, Spanish, and Thai and then back to English to confirm that no major misinterpretations took place during the translation process.

The day before testing, the samples were stored and cooled in a refrigerator (3$5^{\circ} \mathrm{C}$ ). The samples were poured into disposable uncovered opaque plastic cups (appr. $150 \mathrm{ml}$ in size) approximately $1-1.5 \mathrm{~h}$ before testing and were stirred using a plastic disposable spoon just before serving. Approximately $50 \mathrm{ml}$ of sample was served. The samples were served $\left(\sim 5-7^{\circ} \mathrm{C}\right)$ in a randomized order. Consumers were asked to clean their palates with purified water and unsalted crackers after tasting a sample. The consumers completed a ballot and answered questions on a 9-point liking scale where 1 = dislike extremely and 9 = like extremely. The questions included: overall, flavor, sweet taste, sour taste, fruity flavor, pomegranate flavor, and aftertaste liking. The consumers were also asked about flavor, sweetness, sourness, fruitiness, pomegranate flavor, and aftertaste intensities on a 9-point Just-About-Right (JAR) scale where 1 represented "too weak", 5 "Just about right", and 9 "too strong". According to Tuorila (2007) this combination of hedonic and diagnostic questions can provide important information to the reasons that result in differences among consumer perceptions.

\subsection{Data Analysis}

Consumer data were analysed using XL Stat version 2011.1.04 (XL Stat, New York, NY, US). Significant differences $(\mathrm{p}=0.05)$ in products were determined using 
the Fisher's Least Significant Difference (LSD) to compare differences among juices across countries, within a country, and within consumer clusters (across countries). The consumers were clustered using K-means clustering by their flavor liking scores across countries. Wilk's Lambda was used as the clustering criterion and the number of clusters was selected according to the semi-partial R-squared value at 0.05 . Drivers of liking were determined by using external preference mapping (Greenhoff and MacFie, 1994). Consumer clusters flavor liking scores were mapped with descriptive sensory analysis data using Partial Least Squares Regression (Unscrambler vs 10.2, Camo Software, Norway). A similar approach has been used by Drake et al., (2009) and Lee et al., (2010). For JAR data, scores 6-9 were grouped as "too high" and scores 1-4 were grouped as "too low", while scores of 5 were considered as "just about right" (Meilgaard, Civille, and Carr, 2007). Penalty analysis was used to determine if the rankings on the JAR scale were related to significantly different results in the flavor liking scores $(\mathrm{P}<0.05)$. Fisher's LSD test was used for multiple comparison tests of the mean of the JAR level and the mean of the other levels. The sample threshold for penalty analysis was $20 \%$.

\section{Results}

\subsection{Descriptive data}

All descriptive analysis attributes detected in each sample are indicated in Table 2. Sour, sweet, and bitter taste, as well as sweet overall aromatics, astringent and toothetch mouthfeels were found in all samples. The samples were different in the specific aromatic attributes and basic taste and astringency levels. None of the samples was scored in the high range (10.5-15.0) of the scale for any attribute. 
Sample A was sour, astringent and had dark-fruity aromatics. Sample A had less fruity or vegetable aromatics than other samples. Sample B1 had cranberry, fruity and berry aromatics; sample B had cranberry and grape notes; sample C had some musty/earthy and beet notes with a chalky mouthfeel; sample D was sour, astringent, and bitter, and carried fermented and metallic notes. Sample D was the only sample to have bitter taste and astringent mouthfeel linger. Sample E was higher in sweet overall, with cherry and candy-like notes present in addition to the sweet taste. The differences between scores at room temperature versus cold juices did not exceed one point for most attributes, therefore it is reasonable to conclude that the "cold" juices served in the consumer study were representative of the five flavor groupings of pomegranate juices.

\subsection{Consumer study results}

\subsubsection{Acceptability and just-about-right scores across countries}

The flavor of sample A (dark-fruity, sour, and astringent) was disliked in Estonia and the US (no significant differences $\mathrm{p}=0.05$, average scores $<5$ ). The scores for sample A were even lower in Thailand and Spain (Table 3). Most consumers in all four countries evaluated flavor intensity (67-78\%) and sour taste intensity (72$77 \%$ ) of sample A as too high.

Sample B1 was liked moderately in Thailand, and B in Estonia for overall liking, flavor liking, sweet taste liking, sour taste liking, and pomegranate flavor liking (mean score $>6$ ). Moderate liking of sample B1 in Thailand may be accounted for a slightly more pleasant flavor profile of sample B1. However, sample B was evaluated as highly in Estonia, which means no conclusions could be drawn about a potential sample effect on liking. Sample B was the only sample that had average 
scores $>6$ for some liking attributes. However, sample B was not liked in Spain (average score $<5$ ). Sample B was highest in fruity and vegetable-like notes and was moderately sweet. Lee et al. (2010) has also reported differences in liking for certain characteristics between countries: US consumers liked green tea samples that were brown, sweet and fruity, while Thai consumers liked fruity samples most.

Sample C was a Spanish sample with chalky mouthfeel and higher musty/earthy flavor notes. Different varieties of pomegranates (than in the US or Thailand) are grown and processed in Spain. Thus, sample $C$ as a local sample may have a more familiar flavor profile to Spanish consumers than the other samples tested. Even though higher liking towards a familiar sample may be expected, mean scores did not indicate liking or disliking of sample C by Spanish consumers. Sample A was acquired from Estonia, however mean scores did not indicate liking towards this sample by Estonian consumers. A different conclusion was noted by Font $\mathrm{i}$ Furnols et al. (2011), who found that local origin of foods was important to the consumers in a study of local and foreign lamb meats. In a green tea study, Lee et al. (2010) noted that the green teas liked most by US consumers had brown flavor notes often associated with black tea which is more frequently consumed in the U.S, therefore underlining the importance of familiar flavor cues. For sweet and sour taste liking, Estonian, Spanish, and Thai consumers were of similar opinions and found sample C not liked or disliked (average score $>5$ ), whereas Sample C was disliked in the US (average scores $<5$ ).

Consumers, regardless of country, seem to have certain expectations when it comes to pomegranate juice flavor, as was indicated with sample D, which was not liked in any country (average scores $<5$ ). The dislike of sample D may have been caused by the fermented, metallic and high astringent properties which often are 
considered as negative flavor attributes regardless of country. Sample D was scored as too high in sour taste $(73-88 \%)$ and flavor intensity $(80-89 \%)$ by most consumers in all countries.

There were no significant differences between countries in overall liking and sweet taste liking for sample E. The descriptive data showed this sample to be candylike and higher in sweet aromatics, as opposed to the more "natural" flavors of other samples. Sample E was not liked or disliked according to the average scores for overall flavor, sour, and sweet taste attributes in all of the countries, but was not found to be pomegranate-like. Still, the flavor of sample E could be considered as pleasant. The importance of pleasant flavor properties has been discussed in previous literature (Sabbe, Verbeke, Deliza, Matta, \& Van Damme, 2009; Rabino et al., 2007). Results of this study suggest pleasant flavor, but also expected flavor drive consumer liking.

Overall the highest average scores showed only slight liking (6.6 in Thailand, 6.1 in Estonia, 5.8 in USA, and 5.4 in Spain), while the lowest scores indicated slight to strong disliking (2.9 in Spain, 3.4 in thailand, 3.6 in USA, and 4.1 in Estonia) which indicates need for further segmentation of the consumers.

\subsubsection{Consumer Clusters Across Countries}

Clustering across countries revealed five clusters of consumers (Table 5). There were consumers from each country in each of the clusters and their distribution varied from $9.2 \%$ to $50.0 \%$ per cluster. Consumers in cluster 1 liked samples $\mathrm{C}$ and $\mathrm{E}$ and disliked sample D. Over 60\% of this cluster was composed of European (Estonian and Spanish) consumers. Consumers in cluster 2 liked sample B and disliked samples A, C, and D. Over $70 \%$ of this cluster was composed of non European (Thai and US

consumers). Consumers in cluster 3 did not like any sample in particular; sample E 
was neither liked or disliked. Half of the consumers in this cluster were Spanish. Consumers in Cluster 4 liked (average scores $>6$ ) samples A, B, D, and E. Over 60\% of this cluster was composed of Estonian and US consumers. Consumers in cluster 5 liked sample B slightly and disliked samples A, D, and E. Over $60 \%$ of cluster 5 was composed of US and Estonian consumers. The results indicated sample B/B1 (grape, fruity) was accepted by majority of consumers.

Consumer demographic information such as gender, age, education level, as well as behavioral information (juice consumption frequency) was collected during the study (data not shown). Gender, age, education level, or juice consumption frequency of the consumers did not correlate with sample flavor liking of the clusters. Januszewska and Viaene (2001) also found cross-country segments among chocolate consumers and identified frequency of consumption as one of the factors the segments could be discriminated by, while Séménou, Courcoux, Cardinal, Nicod, and Ouisse (2007) found a significant country-effect on smoked-salmon consumer clusters.

\subsubsection{Drivers of Flavor Liking}

Fig. 1 shows the possible drivers for flavor liking and Fig. 2 shows the biplot (scores and loadings) resulting from external preference mapping. It is important when interpreting these maps to remember that the scores used were average flavor liking scores for clusters and many of the scores were low. In fact, these maps may indicate drivers of disliking more than they represent drivers of liking. Clusters $\mathrm{C} 1$, $\mathrm{C} 2, \mathrm{C} 3$, and $\mathrm{C} 5$ are opposite attributes such as metallic, toothetch, sour, astringent, bitter, floral, and fermented. Cluster 5 also is opposite sweet attributes and 4 is pointed slightly towards the floral, sour, astringent, and bitter attributes. Cluster 5 
liked the sample high in grape and fruity flavors, whereas cluster 4 liked all juices except for sample $\mathrm{C}$, the musty/earthy sample.

\section{Discussion}

The major foci of this study were to determine how consumer acceptance towards five different pomegranate juices differed across four countries (Estonia, Spain, Thailand, and the US), to determine whether consumer segments across countries existed and what drove consumer liking for those segments. In addition, if consumer segments could be determined across countries were those segments more similar or more different than differences in countries.

The four countries selected for this study are different in their location, culture, and size. The differences in acceptance in Estonia and Spain indicate several consumer segments within Europe. Interestingly, results from the US and Estonian consumers were quite similar. Reasons for this may be because US and Estonian consumers are more likely to drink bottled juices rather than fresh juices such as those consumed in countries such as Spain and Thailand, where fresh fruit and juice are more available and consumption is higher.

Liking scores for products within a country and across countries (Table 3) generally have a smaller range (maximum range 3.2 , usual $<2.0$ ) than those across consumer clusters (Table 5) (maximum 4.2, usual >3.0). This suggests that cross country comparisons often may not provide the information needed by researchers who desire to study products from a cross-cultural perspective. A more valuable tool may be examination of consumer segments clusters that can be noted across countries.

Several factors, such as familiarity of certain flavors, innate responses to some tastes, and added information (i.e., that it is a healthy food) may have an influence on consumer liking and purchasing decisions. Innate reactions to bitter and sour taste are 
negative and to sweet taste positive (Steiner, 1979). Astringent mouthfeel, often caused by polyphenols and tannins, can be considered a warning mechanism against eating foods potentially harmful (Shimada, 2006), although it is expected in some foods, such as red wine (Gawel, 1998). Sensitivity to astringency varies and it has been found that people with a higher sensitivity to astringent foods also tend to dislike these foods (Dinnella, Recchia, Tuorila, \& Monteleone, 2011). These mechanisms can explain some results found in this study, such as the drivers of disliking found in preference mapping. Such differences in sensitivity are not likely to be country specific, but are more likely derived from individual genetics that cross country borders or personal preferences that are formed over the course of eating experience.

In addition other flavors (e.g., grape and cherry, familiar from different fruits and foods) were present in some pomegranate juice samples that were tested and may have contributed to a higher flavor liking (Pliner \& Stallberg-White, 2000). This may have relevance for the acceptance of sample B (grape and cranberry flavors) which was moderately liked by four of the five clusters, indicating this flavor combination may be highly successful among a large percentage of the consumers. Sample E (candy-like and cherry flavors) was moderately liked by one and well liked by one consumer cluster.

In some countries (such as Spain, Turkey, and others), where pomegranates are locally grown, pomegranate juice can be considered a traditional product, and would be familiar to local consumers. An example is sample C, a Spanish product, that was one of two products most liked by Spanish consumers (Table 3), but liked even more by a cluster of consumers (Table 5) that were not predominantly Spanish. This shows the importance of segmenting consumers into clusters that are not dependent on country. 
Another factor driving the liking of healthy juices may be caused by flavor learning through exposure (Cardello, 1994). This was well demonstrated in cluster 5, which liked samples B and C moderately. Sample E was disliked slightly, and this may be because this group of consumers did not recognize this sample as a pomegranate juice as the aromatics may have been too fruity and even artificial (described by the candy-like attribute in descriptive analysis). Unfortunately, although we know all of these consumers were juice drinkers, we do not know their frequency of pomegranate juice consumption.

\section{Conclusions}

Five pomegranate juice samples, with different flavor characteristics, were evaluated by consumer panels in Estonia, Spain, Thailand, and the US. The liking of the juices appeared to mostly depend on reactions to certain tastes and sensations, and familiarity of the flavor. The pomegranate juice category is versatile in flavors, and not all five samples were equally liked by the consumers. However, moderate liking

toward different profiles was found in some consumer clusters. The implications of this study to the industry include understanding that instead of looking for individual products for certain countries, a set of products that works well across consumer segments for multiple countries may be more appropriate.

\section{Acknowledgements}

The authors would like to thank Kansas State University Sensory Analysis Center staff, Competence Center of Food and Fermentation Technologies staff, Kasetsart University Sensory and Consumer Research Center staff, and Miguel Hernández University staff for their assistance with this study. 


\section{References}

Adhikari, K., Chambers, E.IV., Miller, R., Vázquez-Araújo, L., Bhumiratana, N., \& Philip, C. (2011). Development of a lexicon for beef flavour in intact muscle. Journal of Sensory Studies, 26, 413-420.

Bett-Garber, K.L., Lea, J.M., Champagne, E.T., \& Mcclung, A.M. (2012). Wholegrain rice flavor associated with assorted bran colors. Journal of Sensory Studies, 27, $78-86$

Cardello, A.V. (1994). Consumer expectations and their role in food acceptance. In: Measurement of food preferences, edited by: MacFie, H.J.H., \& Thomson, D.M.H. Chapman \& Hall, New York.

Dinnella, C., Recchia, A., Tuorila, H., \& Monteleone, E. (2011). Individual astringency responsiveness affects the acceptance of phenol-rich foods. Appetite, 56, 633-642.

Drake, S.L., Lopetcharat, K., Clark, S., Kwak, H.S., Lee, S.Y., \& Drake, M.A. (2009). Mapping differences in consumer perception of sharp Cheddar cheese in the United States. Journal of Food Science, 74, 276-285.

Endrizzi, I., Pirretti, G., Calo, D. G., \& Gasperia, F. (2009). A consumer study of fresh juices containing berry fruits. Journal of the Science of Food and Agriculture, $89,1227-1235$. 
Font i Furnols, M., Realini, C., Montossi, F.,Sañudo, C., Campo, M. M., Oliver, M.A., Nute, G.R., \& Guerrero, L. (2011). Consumer's purchasing intention for lamb meat affected by country of origin, feeding system and meat price: A conjoint study in Spain, France and United Kingdom. Food Quality and Preference, 22, 443-45.

Gawel, R. (1998). Red wine astringency: A review. Australian Journal of Grape and Wine Research, 4, 74-95.

Greenhoff, K., \& MacFie, H.J.H. (1994). Ch 6: Preference mapping in practice. In: Measurement of food preferences, edited by: MacFie, H.J.H., \& Thomson, D.M.H. Chapman \& Hall, New York.

Januszewska, R., \& Viaene, J. (2001). Sensory segments in preference for plain chocolate across Belgium and Poland. Food Quality and Preference, 12, 97-107.

Koppel, K., \& Chambers, E. IV. (2010). Development and application of a lexicon to describe the flavor of pomegranate juice. Journal of Sensory Studies, 25, 819-837.

Lee, J., Chambers E. IV, Chambers, D. H., Chun, S. S., Oupadissakoon, C., \& Johnson, D. E. (2010). Consumer acceptance for green tea by consumers in the United States, Korea, and Thailand. Journal of Sensory Studies, 25, 109-132.

Meilgaard, M.C., Civille, G.V., \& Carr, B.T. Sensory evaluation techniques. (2007). CRC Press, Taylor \& Francis Group, 4th Ed. 
Moskowitz, H., Gofman, A., \& Beckley, J. (2006). Using high-level consumerresearch methods to create a tool-driven guidebook and database for product development and marketing. Journal of Sensory Studies, 21, 54-100.

Neely, E.A., Lee, Y., \& Lee, S.-Y. (2010). Cross-cultural comparison of acceptance of soy-based extruded snack foods by U.S. and Indian consumers. Journal of Sensory Studies, 2, 78-108.

Oupadissakoon, G., Chambers, D.H., \& Chambers, E. IV. (2009). Comparison of the sensory properties of ultra-high-temperature (UHT) milk from different countries. Journal of Sensory Studies, 24, 427-440.

Pliner, P., \& Stallberg-White, C. (2000). "Pass the ketchup, please": Familiar flavors increase children's willingness to taste novel foods. Appetite, 34, 95-103.

Rabino, S., Moskowitz, H., Katz, R., Maier, A., Paulus, K., Aarts, P., Beckley, J., \& Ashman, H. (2007). Creating databases from cross-national comparisons of foodmind-sets. Journal of Sensory Studies, 22, 550-586.

Rozin, P., Fischler, C., Imada, S., Sarubin, A., \& Wrzesniewski, A. (1999). Attitudes to food and the role of food in life in the U.S.A., Japan, Flemish Belgium and France: Possible implications for the diet-health debate. Appetite, 33, 163-180. 
Sabbe, S., Verbeke, W., Deliza, R., Matta, V., \& Van Damme, P. (2009). Effect of a health claim and personal characteristics on consumer acceptance of fruit juices with different concentrations of acai (Euterpe oleracea Mart.). Appetite, 53, 84-92.

Séménou, M., Courcoux, P., Cardinal, M., Nicod, H, \& Ouisse, A. (2007). Preference study using a latent class approach. Analysis of European preferences for smoked salmon. Food Quality and Preference, 18, 720-728.

Shimada, T. (2006). Salivary proteins as a defense against dietary tannins. Journal of Chemical Ecology, 32, 1149-1163.

Steiner, J.E. (1979). Preference behaviour and chemoreception. J.H.A. Kroeze (Ed.). London: IRL Press.

Suwonsichon, S., Chambers, E. IV., Kongpensook, V., \& Oupadissakoon, C. (2012). Sensory lexicon for mango as affected by cultivars and stages of ripeness. Journal of Sensory Studies, 27, 148-160.

Tuorila, H. (2007). Ch 2: Sensory perception as a basis of food acceptance and consumption. In: Consumer-led food product development. Woodhead Publishing.

Vázquez-Araújo, L., Chambers, E. IV, Adhikari, K., \& Carbonell-Barrachina, A. A. (2010). Sensory and physicochemical characterization of juices made with pomegranate and blueberries, blackberries, or raspberries. Journal of Food Science, 75, 398-404. 
Viuda-Martos, M., Fernández-López, J., \& Pérez-Álvarez, J.A. (2010). Pomegranate and its many functional components as related to human health: A review.

Comprehensive Reviews in Food Science and Food Safety, 9, 635-654. 
Table 1

Samples tested and their origin

\begin{tabular}{lllll}
\hline Sample & Cluster* & Countries tested in & Country of origin & Country acquired from \\
\hline A $^{* *}$ & 4 & Estonia, US, Spain, Thailand & Azerbaijan & Estonia \\
B & 2 & Estonia, US, Spain & N/A & US \\
B1 ${ }^{* *}$ & 2 & Thailand & N/A & Thailand \\
C & 1 & Estonia, US, Spain, Thailand & Spain & Spain \\
D & 3 & Estonia, US, Spain, Thailand & N/A & US \\
E & 5 & Estonia, US, Spain, Thailand & N/A & US \\
\hline Notes. *According to descriptions by Koppel and Chambers, 2010. & &
\end{tabular}

**Sample not studied by Koppel and Chambers, 2010. 
Table 2

Flavor profiles of the samplesaccording to descriptive sensory analysis flavor profile approach

\begin{tabular}{|c|c|c|c|c|c|c|c|c|c|c|c|c|}
\hline \multirow{2}{*}{$\begin{array}{l}\text { Sample } \\
\text { Attribute }\end{array}$} & \multicolumn{2}{|c|}{ A } & \multicolumn{2}{|c|}{ B1 } & \multicolumn{2}{|c|}{ B } & \multicolumn{2}{|c|}{$\mathrm{C}$} & \multicolumn{2}{|c|}{$\mathrm{D}$} & \multicolumn{2}{|c|}{ E } \\
\hline & room & cold & room & cold & room & cold & room & cold & room & cold & room & cold \\
\hline Astringent & 5.0 & 5.0 & 3.5 & 3.5 & 3.5 & 3.5 & 4.0 & 4.0 & 6.5 & 7.0 & 3.0 & 2.5 \\
\hline Astringent2 & ND & ND & ND & ND & ND & ND & ND & ND & 6.0 & 6.0 & ND & ND \\
\hline Bitter & 4.0 & 4.0 & 4.5 & 4.0 & 4.5 & 4.5 & 4.5 & 4.5 & 5.5 & 5.0 & 3.5 & 3.5 \\
\hline Bitter2 & ND & ND & ND & ND & ND & ND & ND & ND & 4.5 & 4.5 & ND & ND \\
\hline Beet & ND & ND & ND & ND & 2.5 & 2.5 & 4.0 & 3.5 & 2.0 & 2.0 & ND & ND \\
\hline Candy-like & ND & ND & ND & ND & ND & ND & ND & ND & ND & ND & 7.0 & 8.0 \\
\hline $\begin{array}{l}\text { Chalky } \\
\text { mouthfeel }\end{array}$ & ND & ND & ND & ND & ND & ND & 3.0 & 2.5 & ND & ND & ND & ND \\
\hline Cherry & ND & ND & ND & ND & ND & ND & ND & ND & ND & ND & 7.0 & 6.0 \\
\hline Carrot & ND & ND & ND & ND & 2.0 & 2.0 & 4.0 & 3.0 & ND & ND & ND & ND \\
\hline Cranberry & ND & ND & 4.5 & 4.0 & 7.0 & 7.0 & ND & ND & 5.0 & 5.0 & ND & ND \\
\hline Fermented & ND & ND & ND & ND & ND & ND & ND & ND & 5.0 & 5.0 & ND & ND \\
\hline Floral & ND & ND & ND & ND & ND & ND & ND & ND & 2.0 & 2.0 & ND & ND \\
\hline Fruity & ND & ND & 5.5 & 5.5 & ND & ND & ND & ND & 3.5 & 3.5 & 4.0 & 5.0 \\
\hline Grape* & ND & 3.0 & 6.5 & 5.5 & 6.5 & 6.5 & 2.0 & 2.0 & ND & ND & 2.5 & 0.0 \\
\hline Fruity-dark & 5.5 & 4.5 & ND & ND & 3.0 & 3.0 & 4.5 & 4.0 & 3.5 & 3.5 & ND & ND \\
\hline Metallic & ND & ND & ND & ND & 2.0 & 2.0 & 2.0 & 2.0 & 4.0 & 4.0 & ND & ND \\
\hline $\begin{array}{l}\text { Metallic } \\
\text { mouthfeel }\end{array}$ & ND & ND & ND & ND & 3.0 & 3.0 & 4.5 & 4.5 & 5.0 & 5.0 & ND & ND \\
\hline Musty/ earthy & 3.0 & 4.0 & 4.0 & 3.5 & 4.0 & 3.0 & 5.5 & 5.5 & ND & ND & ND & ND \\
\hline Sour & 6.0 & 6.0 & 4.0 & 4.0 & 4.0 & 4.0 & 3.5 & 3.5 & 4.5 & 6.5 & 3.5 & 3.5 \\
\hline Sour2 & 4.5 & 4.5 & ND & ND & 3.5 & 3.5 & 3.5 & 4.0 & 4.0 & 4.0 & ND & ND \\
\hline Sweet & 3.0 & 3.0 & 2.5 & 3.5 & 2.0 & 3.0 & 3.0 & 3.0 & 3.5 & 3.5 & 5.0 & 5.0 \\
\hline Sweet overall & 4.5 & 4.5 & 4.0 & 4.5 & 4.0 & 4.0 & 4.5 & 4.5 & 4.0 & 4.0 & 8.0 & 8.5 \\
\hline Toothetch & 2.5 & 2.5 & 3.0 & 3.0 & 3.0 & 3.0 & 3.5 & 3.5 & 5.0 & 5.0 & 2.0 & 2.0 \\
\hline
\end{tabular}

Sour2, bitter2, astringent $2=$ sour, bitter, and astringent sensations recorded in the end of tasting.

*Grape includes berry aromatics. 
Table 3

Mean scores and ANOVA for overall, flavor, sweet taste, sour taste, fruity, pomegranate, and aftertaste liking for Estonia, Spain, Thailand, and the US

\begin{tabular}{|c|c|c|c|c|c|c|c|c|c|c|c|c|c|}
\hline Country & & Estonia & & & Spain & & & Thailand & & & US & & \\
\hline Sample & Attribute & Mean & $\mathrm{bc}$ & wc & Mean & $\mathrm{bc}$ & wc & Mean & $\mathrm{bc}$ & wc & Mean & $\mathrm{bc}$ & wc \\
\hline \multirow[t]{7}{*}{ A } & Overall & 4.6 & $\mathrm{a}$ & c & 3.6 & $\mathrm{~b}$ & $\mathrm{c}$ & 4.0 & $\mathrm{~b}$ & $\mathrm{c}$ & 4.9 & $\mathrm{a}$ & $\mathrm{b}$ \\
\hline & Flavor & 4.8 & $\mathrm{a}$ & $\mathrm{c}$ & 3.4 & $\mathrm{c}$ & $\mathrm{c}$ & 4.1 & $\mathrm{~b}$ & $\mathrm{c}$ & 4.9 & $\mathrm{a}$ & $\mathrm{b}$ \\
\hline & Sweet & 5.1 & $\mathrm{a}$ & $\mathrm{b}$ & 3.5 & $\mathrm{~b}$ & $\mathrm{c}$ & 4.7 & $\mathrm{a}$ & $\mathrm{c}$ & 5.0 & $\mathrm{a}$ & $\mathrm{bc}$ \\
\hline & Sour & 5.0 & $\mathrm{a}$ & $\mathrm{b}$ & 3.8 & $\mathrm{c}$ & c & 4.5 & $\mathrm{~b}$ & $\mathrm{c}$ & 4.9 & $a b$ & $\mathrm{~b}$ \\
\hline & Fruity & 5.1 & $\mathrm{a}$ & $\mathrm{bc}$ & 3.6 & $\mathrm{c}$ & $\mathrm{c}$ & 4.3 & $\mathrm{~b}$ & $\mathrm{c}$ & 4.9 & $\mathrm{a}$ & $\mathrm{b}$ \\
\hline & Pomegranate & 4.9 & $\mathrm{a}$ & $\mathrm{bc}$ & 3.3 & $\mathrm{c}$ & $d$ & 4.3 & $\mathrm{~b}$ & $\mathrm{~cd}$ & 5.1 & $\mathrm{a}$ & $\mathrm{b}$ \\
\hline & Aftertaste & 4.7 & $\mathrm{a}$ & $\mathrm{b}$ & 3.6 & $\mathrm{c}$ & $\mathrm{c}$ & 4.1 & $\mathrm{~b}$ & $\mathrm{~cd}$ & 4.7 & $\mathrm{a}$ & $\mathrm{bc}$ \\
\hline \multirow[t]{7}{*}{$\mathrm{B} / \mathrm{B} 1$} & Overall & 6.1 & $\mathrm{~b}$ & $\mathrm{a}$ & 4.4 & $\mathrm{c}$ & $\mathrm{b}$ & 6.6 & $\mathrm{a}$ & $\mathrm{a}$ & 5.8 & $\mathrm{~b}$ & $\mathrm{a}$ \\
\hline & Flavor & 6.1 & $\mathrm{~b}$ & $\mathrm{a}$ & 4.5 & $\mathrm{c}$ & $\mathrm{b}$ & 6.7 & $\mathrm{a}$ & $\mathrm{a}$ & 5.7 & $\mathrm{~b}$ & $\mathrm{a}$ \\
\hline & Sweet & 6.1 & $\mathrm{a}$ & $\mathrm{a}$ & 4.2 & $\mathrm{c}$ & $\mathrm{b}$ & 6.5 & $\mathrm{a}$ & $\mathrm{a}$ & 5.5 & $\mathrm{~b}$ & $\mathrm{a}$ \\
\hline & Sour & 5.7 & $\mathrm{~b}$ & $\mathrm{a}$ & 4.4 & $\mathrm{c}$ & $\mathrm{b}$ & 6.3 & $\mathrm{a}$ & $\mathrm{a}$ & 5.5 & $\mathrm{~b}$ & $\mathrm{a}$ \\
\hline & Fruity & 6.0 & $\mathrm{~b}$ & $\mathrm{a}$ & 4.7 & $\mathrm{c}$ & $\mathrm{b}$ & 6.6 & $\mathrm{a}$ & $\mathrm{a}$ & 5.8 & $\mathrm{~b}$ & $\mathrm{a}$ \\
\hline & Pomegranate & 6.3 & $\mathrm{a}$ & $\mathrm{a}$ & 4.5 & $\mathrm{~b}$ & $\mathrm{~b}$ & 6.0 & $\mathrm{a}$ & $\mathrm{a}$ & 6.0 & $\mathrm{a}$ & $\mathrm{a}$ \\
\hline & Aftertaste & 5.6 & $\mathrm{a}$ & $\mathrm{a}$ & 4.3 & $\mathrm{c}$ & $\mathrm{b}$ & 5.8 & $\mathrm{a}$ & $\mathrm{a}$ & 5.0 & $\mathrm{~b}$ & $\mathrm{~b}$ \\
\hline \multirow[t]{7}{*}{$\mathrm{C}$} & Overall & 5.3 & $\mathrm{a}$ & $\mathrm{b}$ & 5.1 & $\mathrm{a}$ & $\mathrm{a}$ & 4.1 & $\mathrm{~b}$ & $\mathrm{c}$ & 4.0 & $\mathrm{~b}$ & $\mathrm{c}$ \\
\hline & Flavor & 5.4 & $\mathrm{a}$ & $\mathrm{b}$ & 5.3 & $\mathrm{a}$ & $\mathrm{a}$ & 4.7 & $\mathrm{~b}$ & $\mathrm{~b}$ & 4.0 & $\mathrm{c}$ & $\mathrm{c}$ \\
\hline & Sweet & 5.5 & $\mathrm{a}$ & $\mathrm{b}$ & 5.7 & $\mathrm{a}$ & $\mathrm{a}$ & 5.5 & $\mathrm{a}$ & $\mathrm{b}$ & 4.7 & $\mathrm{~b}$ & $\mathrm{c}$ \\
\hline & Sour & 5.4 & $\mathrm{a}$ & $a b$ & 5.3 & $\mathrm{a}$ & $\mathrm{a}$ & 5.0 & $\mathrm{a}$ & $\mathrm{b}$ & 4.3 & $\mathrm{~b}$ & $\mathrm{c}$ \\
\hline & Fruity & 5.4 & $a b$ & $\mathrm{~b}$ & 5.6 & $\mathrm{a}$ & $\mathrm{a}$ & 4.8 & $\mathrm{bc}$ & $\mathrm{b}$ & 4.4 & $\mathrm{c}$ & $\mathrm{bc}$ \\
\hline & Pomegranate & 5.0 & $a b$ & $\mathrm{~b}$ & 5.5 & $\mathrm{a}$ & $\mathrm{a}$ & 4.8 & $\mathrm{~b}$ & $\mathrm{~b}$ & 4.6 & $\mathrm{~b}$ & $\mathrm{~cd}$ \\
\hline & Aftertaste & 5.2 & $\mathrm{a}$ & $\mathrm{b}$ & 5.2 & $\mathrm{a}$ & $\mathrm{a}$ & 4.5 & $\mathrm{~b}$ & bc & 4.4 & $\mathrm{~b}$ & $\mathrm{c}$ \\
\hline \multirow[t]{7}{*}{$\mathrm{D}$} & Overall & 4.1 & $\mathrm{a}$ & d & 2.9 & $\mathrm{c}$ & $\mathrm{d}$ & 3.4 & $\mathrm{bc}$ & d & 3.6 & $\mathrm{ab}$ & $\mathrm{c}$ \\
\hline & Flavor & 4.1 & $\mathrm{a}$ & $\mathrm{d}$ & 2.9 & $\mathrm{c}$ & $\mathrm{c}$ & 3.8 & $\mathrm{ab}$ & $\mathrm{c}$ & 3.5 & $\mathrm{~b}$ & $\mathrm{c}$ \\
\hline & Sweet & 4.6 & $\mathrm{a}$ & $\mathrm{c}$ & 3.0 & $\mathrm{c}$ & $\mathrm{c}$ & 3.8 & $\mathrm{~b}$ & d & 3.9 & $\mathrm{~b}$ & d \\
\hline & Sour & 4.1 & $\mathrm{a}$ & $\mathrm{c}$ & 3.0 & $\mathrm{c}$ & d & 3.4 & $\mathrm{bc}$ & $\mathrm{d}$ & 3.7 & $a b$ & d \\
\hline & Fruity & 4.8 & $\mathrm{a}$ & $\mathrm{c}$ & 3.2 & $\mathrm{c}$ & $\mathrm{c}$ & 4.0 & $\mathrm{~b}$ & $\mathrm{c}$ & 4.3 & $a b$ & $\mathrm{c}$ \\
\hline & Pomegranate & 4.6 & $\mathrm{a}$ & $\mathrm{c}$ & 2.8 & $\mathrm{c}$ & $\mathrm{d}$ & 3.9 & $\mathrm{~b}$ & d & 4.3 & $\mathrm{ab}$ & $\mathrm{d}$ \\
\hline & Aftertaste & 4.1 & $\mathrm{a}$ & c & 3.1 & $\mathrm{c}$ & $\mathrm{c}$ & 3.7 & $\mathrm{ab}$ & $\mathrm{d}$ & 3.5 & $\mathrm{bc}$ & d \\
\hline \multirow[t]{7}{*}{$\mathrm{E}$} & Overall & 5.6 & $\mathrm{a}$ & $\mathrm{b}$ & 5.4 & $\mathrm{a}$ & $\mathrm{a}$ & 5.4 & $\mathrm{a}$ & $\mathrm{b}$ & 5.7 & $\mathrm{a}$ & $\mathrm{a}$ \\
\hline & Flavor & 5.6 & $\mathrm{a}$ & $\mathrm{ab}$ & 5.7 & $\mathrm{a}$ & $\mathrm{a}$ & 5.0 & $\mathrm{~b}$ & $\mathrm{~b}$ & 5.7 & $\mathrm{a}$ & $\mathrm{a}$ \\
\hline & Sweet & 5.5 & $\mathrm{a}$ & $\mathrm{b}$ & 5.7 & $\mathrm{a}$ & $\mathrm{a}$ & 5.3 & $\mathrm{a}$ & $\mathrm{b}$ & 5.4 & $\mathrm{a}$ & $\mathrm{ab}$ \\
\hline & Sour & 5.7 & $\mathrm{a}$ & $\mathrm{a}$ & 5.3 & $a b$ & $\mathrm{a}$ & 5.4 & $\mathrm{ab}$ & $\mathrm{b}$ & 5.2 & $\mathrm{~b}$ & $\mathrm{ab}$ \\
\hline & Fruity & 5.5 & $a b$ & $\mathrm{~b}$ & 4.9 & $\mathrm{~b}$ & $\mathrm{~b}$ & 5.3 & $\mathrm{ab}$ & $\mathrm{b}$ & 5.7 & $\mathrm{a}$ & $\mathrm{a}$ \\
\hline & Pomegranate & 4.7 & $\mathrm{a}$ & bc & 3.9 & $\mathrm{~b}$ & $\mathrm{c}$ & 4.9 & $\mathrm{a}$ & $\mathrm{b}$ & 4.9 & $\mathrm{a}$ & $\mathrm{bc}$ \\
\hline & $\begin{array}{l}\text { Aftertaste } \\
\text { to available: } \mathrm{ES}=\end{array}$ & 5.6 & $\mathrm{a}$ & $\mathrm{a}$ & 5.2 & $\mathrm{ab}$ & $\mathrm{a}$ & 4.7 & $\mathrm{~b}$ & $\mathrm{~b}$ & 5.5 & $\mathrm{a}$ & $\mathrm{a}$ \\
\hline
\end{tabular}


Table 4

Responses to overall flavor, sweet, sour, and aftertaste, fruity and pomegranate flavor intensity as Too low, Just About Right (JAR), or Too high by \% of consumers

\begin{tabular}{|c|c|c|c|c|c|c|c|c|c|c|c|c|c|c|c|}
\hline Intensity & & A & & & $\mathrm{B} / \mathrm{B} 1$ & & & $\mathrm{C}$ & & & $\mathrm{D}$ & & & $\mathrm{E}$ & \\
\hline Estonia & $\begin{array}{l}\text { Too } \\
\text { low }\end{array}$ & JAR & $\begin{array}{l}\text { Too } \\
\text { high }\end{array}$ & $\begin{array}{l}\text { Too } \\
\text { low }\end{array}$ & JAR & $\begin{array}{l}\text { Too } \\
\text { high }\end{array}$ & $\begin{array}{l}\text { Too } \\
\text { low }\end{array}$ & JAR & $\begin{array}{l}\text { Too } \\
\text { high }\end{array}$ & Too low & JAR & Too high & Too low & JAR & Too high \\
\hline Overall flavor & 16.7 & $14.7^{*}$ & $67.6^{*}$ & 3.9 & 24.5 & 71.6 & $42.1^{*}$ & $35.4^{*}$ & $22.5^{*}$ & 7.8 & 6.9 & 84.3 & $32.3^{*}$ & $31.5^{*}$ & 36.2 \\
\hline Sweet taste & $50.0 *$ & $30.4^{*}$ & 19.6 & $24.5^{*}$ & $48.1^{*}$ & 26.4 & 14.7 & $33.4^{*}$ & $51.9^{*}$ & $64.7 *$ & $23.5^{*}$ & 10.8 & 2.9 & $23.6^{*}$ & $73.5^{*}$ \\
\hline Sour taste & 3.9 & $23.6^{*}$ & $72.5^{*}$ & 8.8 & $34.3^{*}$ & $56.8^{*}$ & $60.8 *$ & $36.3^{*}$ & 2.9 & 6.8 & $8.8^{*}$ & $83.3^{*}$ & $47.0 *$ & $38.3^{*}$ & 14.7 \\
\hline Fruity flavor & $49.0 *$ & $15.7^{*}$ & 35.3 & 19.6 & 34.3 & 45.1 & $43.1 *$ & $31.4^{*}$ & 25.5 & $41.1^{*}$ & $17.7 *$ & 40.2 & $45.1^{*}$ & $29.4^{*}$ & $25.5^{*}$ \\
\hline $\begin{array}{l}\text { Pomegranate } \\
\text { flavor }\end{array}$ & $47.0^{*}$ & $18.6^{*}$ & 29.4 & 15.7 & 32.3 & 49.0 & $58.8 *$ & $29.4^{*}$ & 6.8 & $37.2 *$ & $17.6^{*}$ & 41.1 & $75.5^{*}$ & $13.7^{*}$ & 3.9 \\
\hline Aftertaste & 19.6 & $24.5^{*}$ & $55.8 *$ & 4.9 & $35.2 *$ & 59.8 & $35.3 *$ & $46.1^{*}$ & 18.6 & 7.8 & $13.7^{*}$ & $77.4^{*}$ & $27.4^{*}$ & $43.1^{*}$ & $29.4^{*}$ \\
\hline \multicolumn{16}{|l|}{ Spain } \\
\hline Overall flavor & $21.0 *$ & $7.0 *$ & $72.0 *$ & 5.0 & $17.0 *$ & $78.0 *$ & $31.0 *$ & $37.0 *$ & $32.0 *$ & 15.0 & 3.0 & 82.0 & $32.0 *$ & $31.0^{*}$ & $37.0^{*}$ \\
\hline Sweet taste & $72.0 *$ & $15.0^{*}$ & 13.0 & 55.0 & $27.0^{*}$ & $18.0^{*}$ & $32.0 *$ & $32.0 *$ & 36.0 & $75.0^{*}$ & $6.0^{*}$ & 19.0 & 12.0 & $3.0^{*}$ & $58.0^{*}$ \\
\hline Sour taste & 12.0 & $11.0^{*}$ & $77.0 *$ & 11.0 & $17.0^{*}$ & $72.0^{*}$ & 49.0 & 35.0 & 16.0 & 9.0 & $3.0 *$ & $88.0 *$ & $53.0^{*}$ & $33.0^{*}$ & 14.0 \\
\hline Fruity flavor & $55.0^{*}$ & $9.0^{*}$ & $36.0 *$ & $31.0 *$ & $21.0^{*}$ & $48.0^{*}$ & $30.0 *$ & $36.0 *$ & 34.0 & $58.0^{*}$ & $10.0^{*}$ & $32.0^{*}$ & 49.0 & $31.0^{*}$ & 20.0 \\
\hline $\begin{array}{l}\text { Pomegranate } \\
\text { flavor }\end{array}$ & $69.0 *$ & $9.0^{*}$ & $22.0 *$ & $45.0^{*}$ & $24.0 *$ & 31.0 & $32.0 *$ & $36.0 *$ & 32.0 & $76.0^{*}$ & $6.0 *$ & 18.0 & $82.0^{*}$ & $13.0^{*}$ & 5.0 \\
\hline Aftertaste & $30.0 *$ & $13.0 *$ & $57.0 *$ & 15.0 & $30.0 *$ & $55.0^{*}$ & $27.0 *$ & $36.0^{*}$ & $36.0^{*}$ & $26.0 *$ & $10.0 *$ & $64.0 *$ & $38.0^{*}$ & $40.0^{*}$ & $21.0^{*}$ \\
\hline \multicolumn{16}{|l|}{ Thailand } \\
\hline Overall flavor & 9.1 & $12.8^{*}$ & $78.1^{*}$ & $20.9 *$ & $59.1 *$ & 20.0 & 11.8 & $31.8^{*}$ & $56.4^{*}$ & 10.0 & $16.4^{*}$ & $73.6^{*}$ & 11.8 & $30.0^{*}$ & $58.2 *$ \\
\hline Sweet taste & $61.8 *$ & $24.6^{*}$ & 13.6 & $28.2^{*}$ & $57.3^{*}$ & 14.5 & 19.1 & $46.4 *$ & $34.5^{*}$ & $79.1 *$ & $13.6^{*}$ & 6.3 & $48.2 *$ & $33.6^{*}$ & 18.2 \\
\hline Sour taste & 7.3 & $17.3^{*}$ & $75.4^{*}$ & 10.9 & $58.2 *$ & $30.9 *$ & $65.4 *$ & $26.4^{*}$ & 8.2 & 15.4 & $2.7^{*}$ & $80.9 *$ & $23.6^{*}$ & $29.1^{*}$ & $47.3^{*}$ \\
\hline Fruity flavor & 13.6 & $17.3^{*}$ & $69.1 *$ & $21.8^{*}$ & $63.7^{*}$ & 14.5 & 17.2 & $33.7^{*}$ & $49.1 *$ & 20.0 & $12.7 *$ & $66.3^{*}$ & 13.6 & $32.8^{*}$ & $53.6^{*}$ \\
\hline $\begin{array}{l}\text { Pomegranate } \\
\text { flavor }^{c}\end{array}$ & 10.0 & $4.5^{*}$ & $20.9 *$ & $23.6^{*}$ & $28.2 *$ & 8.1 & 7.2 & $17.3^{*}$ & $22.7 *$ & 10.9 & $3.6^{*}$ & $27.2 *$ & 9.1 & $8.2 *$ & 20.0 \\
\hline Aftertaste & 4.5 & $19.2 *$ & $76.3 *$ & 10.9 & $63.6^{*}$ & $25.5^{*}$ & 13.6 & $33.7^{*}$ & $52.7^{*}$ & 3.6 & $10.9 *$ & $85.5^{*}$ & 10.0 & $32.7 *$ & $57.3^{*}$ \\
\hline \multicolumn{16}{|l|}{ US } \\
\hline Overall flavor & 12.8 & $19.8^{*}$ & $67.3 *$ & 3.9 & $23.8^{*}$ & $72.3^{*}$ & $35.6 *$ & $22.8^{*}$ & $41.6^{*}$ & 5.0 & $6.9^{*}$ & $88.1^{*}$ & $25.7 *$ & $38.6^{*}$ & $35.6^{*}$ \\
\hline Sweet taste & $55.5^{*}$ & $22.8^{*}$ & 21.7 & $45.5^{*}$ & $31.7^{*}$ & $22.8^{*}$ & $25.7 *$ & $35.7^{*}$ & $38.6^{*}$ & $70.3^{*}$ & $16.8^{*}$ & 12.9 & 7.9 & $26.7^{*}$ & $64.4^{*}$ \\
\hline
\end{tabular}




\begin{tabular}{|c|c|c|c|c|c|c|c|c|c|c|c|c|c|c|c|}
\hline Sour taste & 6.9 & $19.8^{*}$ & $73.2 *$ & 3.9 & $36.7 *$ & $59.4 *$ & $58.4 *$ & $26.7 *$ & 14.9 & 1.0 & $9.9 *$ & $89.1 *$ & $56.5^{*}$ & $35.6^{*}$ & 6.9 \\
\hline Fruity flavor & $45.5^{*}$ & $14.9 *$ & $39.6^{*}$ & $24.7 *$ & $32.7 *$ & 42.6 & $55.5^{*}$ & $17.8^{*}$ & $26.7 *$ & $45.5^{*}$ & $13.9 *$ & $40.6^{*}$ & $33.7 *$ & $29.7 *$ & $35.6^{*}$ \\
\hline $\begin{array}{l}\text { Pomegranate } \\
\text { flavor }^{\mathrm{d}}\end{array}$ & $27.7^{*}$ & $24.7 *$ & $38.6^{*}$ & 15.8 & $36.6^{*}$ & 39.6 & $45.5^{*}$ & $15.8^{*}$ & 20.8 & $31.6^{*}$ & $13.9 *$ & $41.5^{*}$ & $51.5^{*}$ & $21.8^{*}$ & 9.9 \\
\hline Aftertaste & 6.9 & $38.6^{*}$ & $54.4 *$ & 3.9 & $42.6^{*}$ & $52.4 *$ & 15.8 & $42.6^{*}$ & $39.6^{*}$ & 5.0 & $16.8 *$ & $78.2 *$ & 16.8 & $52.5^{*}$ & $28.7 *$ \\
\hline
\end{tabular}

Pomegranate flavor intensity was evaluated by $35-60 \%$ respondent

d Pomegranate flavor intensity was evaluated by $82-98 \%$ respondents

$* \mathrm{P}<0.05$, comparison test of the mean for the attribute intensity level are related to a significant difference in liking scores. 
Table 5

Mean values and ANOVA for flavor liking for consumer clusters and consumer distribution \% across countries*

\begin{tabular}{|c|c|c|c|c|c|c|c|c|c|c|}
\hline \multicolumn{11}{|c|}{ Cluster } \\
\hline Sample & C1(80) & & C2(98) & & C3(84) & & C4(72) & & C5(77) & \\
\hline A & 5.2 & b & 4.1 & $\mathrm{c}$ & 2.8 & d & 6.0 & $\mathrm{a}$ & 3.6 & $\mathrm{c}$ \\
\hline $\mathrm{B} / \mathrm{B} 1$ & 6.1 & b & 6.7 & $\mathrm{a}$ & 2.8 & $\mathrm{c}$ & 6.8 & $\mathrm{a}$ & 6.6 & $\mathrm{a}$ \\
\hline $\mathrm{C}$ & 7.0 & $\mathrm{a}$ & 2.8 & $\mathrm{e}$ & 4.2 & d & 4.9 & $\mathrm{c}$ & 5.9 & b \\
\hline D & 3.2 & b & 3.3 & $\mathrm{~b}$ & 2.2 & $\mathrm{c}$ & 6.4 & $\mathrm{a}$ & 3.0 & b \\
\hline $\mathrm{E}$ & 7.1 & $\mathrm{a}$ & 5.5 & $\mathrm{c}$ & 5.8 & $\mathrm{bc}$ & 6.1 & $\mathrm{~b}$ & 2.9 & d \\
\hline \multicolumn{11}{|c|}{ Consumer distribution $\%$} \\
\hline Estonia & 33.7 & & 17.4 & & 15.5 & & 30.6 & & 27.2 & \\
\hline Spain & 28.8 & & 9.2 & & 50.0 & & 15.3 & & 19.5 & \\
\hline Thailand & 18.7 & & 36.7 & & 22.6 & & 22.2 & & 19.5 & \\
\hline US & 18.8 & & 36.7 & & 11.9 & & 31.9 & & 33.8 & \\
\hline
\end{tabular}




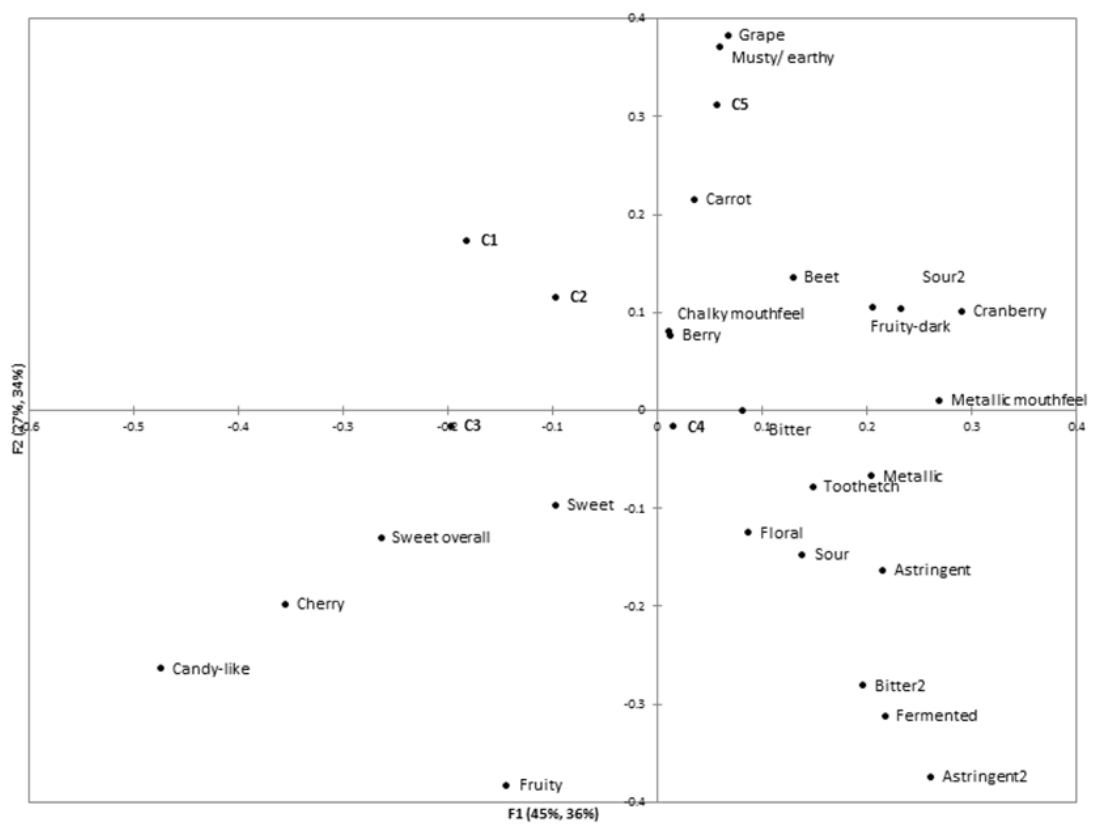

Fig. 1. External preference mapping. C1-C5 stand for cluster 1 - cluster 5, respectively. 


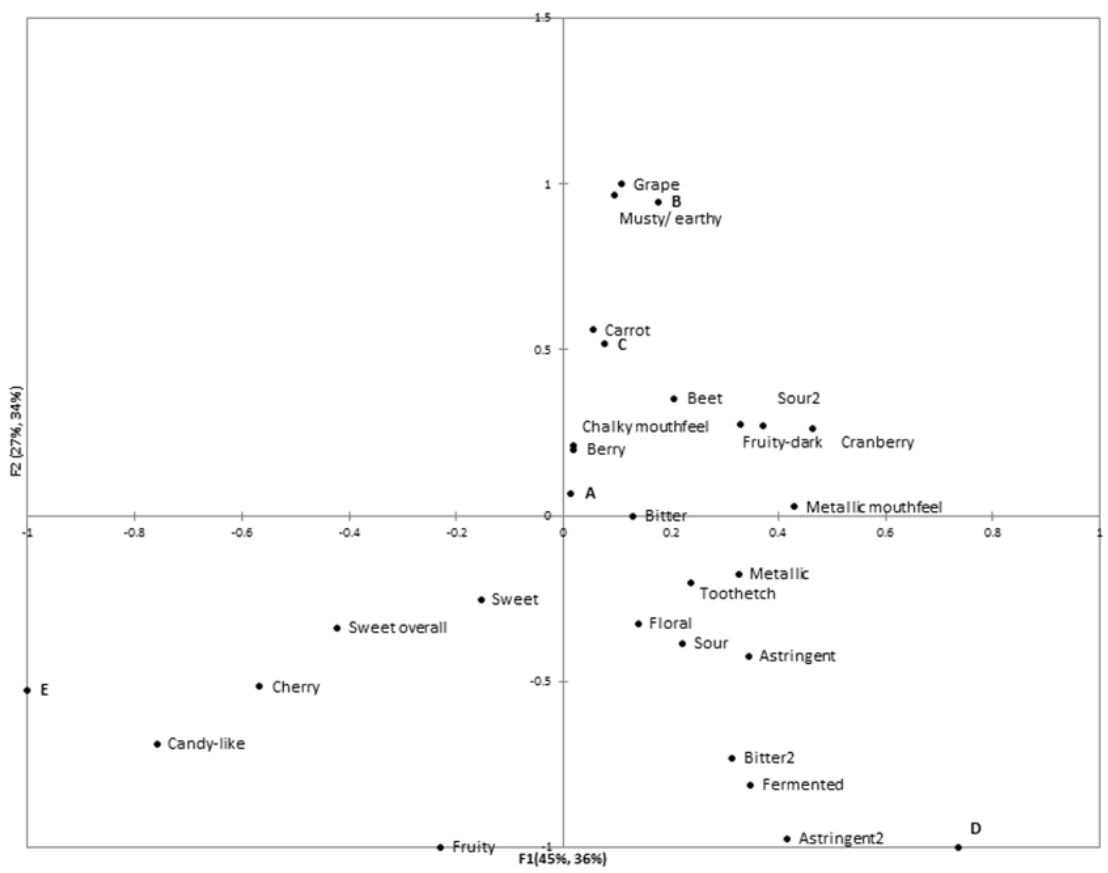

Fig. 2. Scores and loadings plot from external preference mapping. 